\title{
Slovar srednjemoravskega narečja Jarmile Vojtove
}

\begin{abstract}
Mateja Kosi
Jarmila Vojtová, Slovník středomoravského nářečí horského typu, Brno: Masarykova univerzita, 2008, 279 str.

Delo Slovník středomoravského nářečí horského typu (Slovar srednjemoravskega narečja hribovskega tipa) je nastalo na podlagi avtoričine doktorske disertacije. Hribovsko podnarečje iz naslova je v češki dialektologiji termin za podtip (podnarečje) južnega srednjemoravskega narečja v okviru srednjemoravske narečne skupine, ki se govori severozahodno od Brna v okolici Tišnova, Blanska in Sloupa. Delo je vsekakor velik prispevek k ohranjanju kulturne dediščine obravnavanega področja in vsestransko zanimivo za ljubitelje čeških narečij.

Ključne besede: češka narečja, narečni slovar, slovaropisje

\section{The dictionary of the mountain-type central Moravian dialect by Jarmila Vojtová}

The volume Slovnik středomoravského nářeči horského typu (Dictionary of the mountain-type central Moravian dialect) was created based on the author's doctoral dissertation. The mountain-type subdialect in the title is a Czech dialectology term referring to a subtype (or subdialect) of the south central Moravian dialect as part of the central Moravian dialect group, which is spoken northwest of Brno in the vicinity of Tišnov, Blansko, and Sloup. The work is a great contribution to preserving the cultural heritage of this area and has general appeal for those interested in Czech dialects.
\end{abstract}

Key words: Czech dialects, dialect dictionary, lexicography

Slovar srednjemoravskega narečja hribovskega tipa (Slovník středomoravského nářčr horského typu) Jarmile Vojtove ${ }^{1}$ je nastal na podlagi avtoričine doktorske disertacije. Hribovsko podnarečje iz naslova je v češki dialektologiji termin za podtip (podnarečje) južnega srednjemoravskega narečja v okviru srednjemoravske narečne skupine, ${ }^{2}$ ki se govori severozahodno od Brna v okolici Tišnova, Blanska in Sloupa.

1 Jarmila Vojtová je nekdanja sodelavka Inštituta za češki jezik Češke akademije znanosti, od leta 1999 predavateljica na Oddelku za češki jezik Filozofske fakultete Masarykove univerze v Brnu.

2 To je poskus prenosa češke strukture klasifikacije narečij v slovensko. Po njej ima češki jezik 4 narečne skupine z narečji in podnarečji (in brez zamejitve krajevnih govorov). 
Od drugih srednjemoravskih narečij izstopa zaradi posebnosti v razvoju kratkega vokalizma, in sicer zaradi zamenjave $o$ in $u$, npr. kopec za češko 'kupec', slov. 'kupec', in kupec za češko 'kopec', slov. 'grič, hribček'.

Delo, ki je po besedah avtorice za zdaj prvo, ki popisuje stanje in razvoj narečnega besedja $v$ mikroarealu na zahodnem Moravskem po najnovejših leksikografskih metodah (str. 3), je razdeljeno na štiri poglavja, in sicer na uvod (str. 7-25), diferencialni slovar s slikovno prilogo (str. 27-167), ${ }^{3}$ ideografski geslovnik oz. indeks, torej predstavitev besedja po pomenskih poljih (str. 169-227), in abecedno kazalo vključenih leksemov (str. 229-279).

V uvodu so najprej predstavljene zemljepisne in gospodarske značilnosti raziskovanega področja, to je hribovitega predela Češkomoravskega hribovja (Tišnovsko) in Drahanske planine (Blanensko). Sledi historiat raziskav tega narečja. Iz popisa zbranega narečnega gradiva je podano splošno znanje o strukturnih značilnostih in razvojnih tendencah moravskih narečij, predstavljena pa je še metoda zbiranja in obdelave narečnega izrazja. Izhodiščni korpus za sestavo slovarja je bil zbran v letih 1988-1998 in je nastal na podlagi avtoričinega terenskega dela $v$ šestih izbranih krajih: Deblín, Drásov, Lažany-Lipůvka, Podlesí, Rájec-Jestřebí in Sloup, ${ }^{4}$ v raziskavo je bilo vključenih 30 informatorjev. Avtorica je želela zajeti predvsem najstarejšo podobo narečja in na tej osnovi predstaviti njegove tipične značilnosti in razvojne tendence, zato je $\mathrm{v}$ raziskavo vključila tudi izpolnjeno vprašalnico za Češki jezikovni atlas (Český jazykový atlas 1-5, ČJA, 1992-2005) Slovníkový dotazník pro výzkum českých nářčci (1954 in 1958) in gradivo iz slovarja F. Bartoša Dialektický slovník moravský (1906), kar je označeno s krajšavo Bš. Zbrala je okrog 9000 leksikalnih enot, ki predstavljajo razmeroma kompletno narečno leksiko.

Sledi podpoglavje Leksikografska obdelava narečnega gradiva, v katerem je avtorica opisala tip diferencialnega razlagalnega slovarja in nato sestavo gesla v svojem slovarju, predstavila ideografski geslovnik oz. indeks besed, razvrščenih po pomenskih poljih, ter podala kratko analizo narečnega gradiva. Sledijo še uporabljene kratice in krajšave ter literatura. Besedje je zapisano v poenostavljeni fonetični transkripciji, ki se na Češkem uporablja po pravilih za znanstveni prepis narečnih zapisov (Pravidla pro vědecký přepis dialektických zápisů, Věstník Česke akademie věd a uméni 52 (1953), 63-68).

Sledi obsežno osrednje poglavje semaziološko ${ }^{5}$ zasnovanega diferencialnega $^{6}$ slovarja s slikovno prilogo. Vsebuje 1180 gesel, v katerih je 293 leksemov za-

3 Slikovna priloga je vključena na str. 159-167. Slik oz. risb je 10.

4 Območje je prikazano na zemljevidu na naslovnici knjige. Kraji, v katerih je potekala raziskava, so obarvani rdeče.

5 Do zdaj nastali slovenski narečni slovarji so pripravljeni s semaziološkega vidika, v katerem je koncept usmerjen od besede k razlagi (po Hartmann - James 1998: 102).

6 Tudi večina slovenskih semazioloških slovarjev je zasnovana diferencialno. Po terminologiji Karmen Kenda-Jež in Petra Weissa so slovenski narečni slovarji razdeljeni na kontrastivne, to je zasnovane kontrastivno s knjižnim jezikom, in konfrontativne slovarje, ki sopostavljajo leksiko dveh sistemov - narečnega in knjižnega - istega diasistema, narečno besedje pa je pojmovano kot skupek leksikalnih enot narečja (Kenda-Jež - Weiss 1999: 28-30). Vsenarečni slovar naj bi bil že po definiciji kontrastivni, slovar določenega 
pisanih povsem na novo, vključeno pa je le diferencialno izrazje, torej tisto, ki se razlikuje od knjižnega. To pomeni, da je bilo celotno besedje vključeno v onomaziološko zasnovani ideografski indeks besed, primerjan s Slovarjem češkega knjižnega jezika (Slovník spisovného jazyka českého 1-8, SSJČ, 1960-1971). Po že znanih načelih primerjave so diferencialni tisti izrazi, (1) ki jih v SSJČ ni, (2) ki so v SSJČ označeni kot narečni, ljudski ali pokrajinski, (3) ki so vključeni z drugim pomenom ali drugačnim tipom uporabe in (4) izrazi z besedotvornimi, morfološkimi ali nepravilnimi glasoslovnimi spremembami (Bachmannová 2009: 36). Po drugi strani pa izrazi, ki so drugačni le po pričakovanih glasoslovnih narečnih, pokrajinskih ali jezikovnoplastnih spremembah (tj. iz pogovorne, t. i. »mluvene« češčine), niso označeni kot diferencialni.

Geslo diferencialnega slovarja je sestavljeno zelo pregledno (prepis je tudi oblikovno enak tistemu v knjigi), npr.:

frfňit se, -ím se, pufrfňené ned. nimrat se (zprav. v jídle)

expr.

SSJČ nár. expr., Bš

Srov.: drápat se, mrvit se, šošňit se

Odvoz:: pu-, rus-, du-

26-19

kulípke, -bek, plt. nerovnoměrně vysoké strniště

(SSJČ kolíbky nář. ,hrst posečeného obilí‘, Bš dělat kolibke »pokosy ovsa shrabovati v hrómadky, co by mohl vzíti do náruči«) ČJA III-68

Srov.: pudřatke

32-46-1

kúň, kuňa, m. kobylka, skákavý hmyz žijicí v trávě nebo na stromech

Bš/Kt, ČJA II-48

Dem.: kuňík, kuňíček

19-93

stulička, -e, f.

1. šárka (viz obr. 7)

(SSJČ stolice, sedátko, lavice) ČJA III-135

33-21

2. část dřevěných plužních koleček (viz obr. 9)

ČJA III-46

Srov.: putkladek

32-42-3

govora pa konfrontativni. Konfrontativni so tile slovenski narečni slovarji: Thesaurus der slowenischen Volkssprache in Kärnten 1-6- (1982-2009-), Ludwig Karničar, Der Obir-Dialekt in Kärnten (slovarski del, 1990), Han Steenwijk, The Slovene dialect of Resia: San Giorgio (slovarski del, 1992), Peter Weiss, Slovar govorov Zadrečke doline med Gornjim Gradom in Nazarjami: poskusni zvezek (A-H) (1998). Drugi slovenski narečni slovarji so zasnovani kontrastivno. 
ščerbák, -a, m. člověk s mezerou mezi zuby

Bš ščerbáč »člověk, kterému chybí zub«, ščerbatý »zubatý

20-24-4

+trachtír, -o/-a, m. trychtýř, nálevka

$31-51$

Iztočnici sledijo t. i. osnovne slovarske oblike in knjižna ustreznica oz. opis pomena. Če je beseda povezana s slikovno prilogo, za knjižno ustreznico sledi kazalka viz obr. 'glej sliko' s številko slike (prim. geslo stulička). Dodana je še morebitna raba iztočnice v stalnih besednih zvezah in frazemih, npr. dlóhé jak bidlu pod geslom bidlu (str. 33). Ponekod je dodan kvalifikator expr. - ekspresivno (prim. geslo frfñit se). V geselskem članku najdemo tudi kazalko na geslo v SSJČ, geslo je predstavljeno tudi s stališča odvisnosti s starejšimi raziskavami - zabeležene so vzporednice v Bartoševem slovarju (1906), bralec pa je usmerjen tudi na narečno karto v Češkem jezikovnem atlasu (ČJA) (prim. geslo kulipke). ${ }^{7} \mathrm{~V}$ istem geslu so predstavljeni tudi pomensko bližnji izrazi, kot v geslu ščerbák (tudi ščerbáč iz Bš). Lahko je dodana manjšalnica (prim. geslo kúň). Pri glagolih so za kazalko Odvoz. (= odvozené podoby slova) navedene izpeljanke, večinoma vidski par (prim. geslo frfñit se). Na žalost za posamezni leksem ni podatka, v katerem od raziskovanih krajev se je pojavil, dobro pa bi bilo dodati tudi ponazarjalno gradivo.

Sledi še številčna kazalka na onomaziološki del, torej ideografski geslovnik oz. indeks (npr. 19-93), kar je zelo uporabno, saj ta tip kazalk v slovarjih, ki so brez njih, npr. v NTC's Dictionary of Commonplace Words in Real-Life Contexts avtorice Anne Bertram, za lažjo orientacijo po knjigi manjka. Simbol za plus pred geslom nakazuje, da gre za generacijsko omejen izraz, ki živi kot pasivni besedni zaklad (arhaično, starinsko, prim. geslo +trachtír). Po oceni Stanislave Kloferove (2009: 33) gre za prvi češki narečni slovar, ki h geslu umešča tudi tako izdelan sistem kazalk in simbolov.

Tretje poglavje je posvečeno onomaziološko ${ }^{8}$ zasnovani predstavitvi besed po pomenskih poljih (ideografskemu geslovniku). Izrazi so po pomenskih poljih razvrščeni v štiri skupine po zgledu Halligove in Wartburgove tradicionalne klasifikacijske sheme (Kloferová 2009: 308) ob upoštevanju prakse slovarja Český slovník věcný a synonymický in po zgledu slovarjev Podkrkonošský slovník Jarmile Bachmannove (1998) in Lašská slovní zásoba Zdeňke Sochove (2001): (I) Vesolje, svet okrog nas, (II) Človek, (III) Človek in družba in (IV) Odnosi splošnega

7 Kratica Kt v seznamu kratic manjka, pomeni pa Kottove dodatke k Bartoševemu slovarju (Bachmannová 2009: 36).

8 Po razlagi v delu Dictionary of Lexicography (Hartmann - James 1998: 101-102) onomaziološki slovar predstavlja besedje in besedne zveze kot izraze pomensko povezanih konceptov, kot so pomeni, ideje, zaznamki, besedne družine in podobna razmerja. Pomembno merilo je usmerjenost od razlage pomena $\mathrm{k}$ besedi raje kot od besede $\mathrm{k}$ razlagi (kot v semazioloških slovarjih). Onomaziološki slovar vodi uporabnika od relativno dobro poznanih konceptov k relativno manj znanim besedam v nasprotju s tradicionalnimi semaziološkimi slovarji, $\mathrm{v}$ katerih so relativno neznane besede razložene s poznanimi. 
značaja. Vsaka od skupin se deli še na podskupine; oštevilčenje večstopenjske hierarhične strukture pa ni preprosto razumljivo. ${ }^{9}$ Podskupine imajo številke I: $10-19$, II: 20-29, III: 30-45, IV: 46-52, te pa se še delijo, npr. 1. in 2. podskupina pomenskega polja 38 Veřejná správa ('javna uprava’), ki spada v III. skupino Človek in družba, na kar nas usmeri prva številka v številčenju pomenskega polja, je:

\section{Veřejná správa}

38-1 prezident

parlament

senát

vláda, přeceda vláde

ministr

38-2 policije

policajt

esenbák, četňík

velitel

38-21 harest/harešt, vjezeňí, šatlava

sed'et

bachar̆

amnestije

38-3 zákon

paragraf

žalovat

sód

sóci, sóce

porota

$[\ldots]$

Posamezni izrazi v ideografskem geslovniku niso razloženi, saj njihov pomen izhaja iz konteksta. Posebej dragocena je vključitev izbora lastnih imen, in sicer lastnih imen bitij in zemljepisnih lastnih imen z ledinskimi imeni (mikrotoponimi). Izmed 9000 leksikalnih enot so s krepkim tiskom označene enote diferencialnega slovarja. Žal si skupine v razdelkih, kot sta $38-1$ in $38-2$ v prepisanem primeru, sledijo brez vsake prazne vrstice in torej novo podenoto označujejo le spredaj zapisane številke. Uporabno bi bilo, če bi bili posamezni leksemi v skupini navedeni po abecednem vrstnem redu. Leksem sóci 'sodnik' je zapisan krepko, kar pomeni, da ga najdemo v diferencialnem slovarju (vendar je enak slog izbran tudi za označitev novega po-

9 Zelo dober in enostaven sistem kazalk ima na primer onomaziološko zasnovani slovar Sistematski rečnik srpskohrvatskoga jezika (Jovanović - Atanacković 1980), v katerem so geselski članki celega slovarja zaporedno oštevilčeni od 1 do 3906, kljub temu da v vsako pomensko polje spada le po nekaj iztočnic, npr. pod pomensko polje medicina sodijo iztočnice, oštevilčene od 3741 do 3797 (na žalost ta izbor iztočnic znotraj pomenskega polja ni abecedno razvrščen, kar pogrešam tudi v predstavljenem slovarju J. Vojtove). V indeksu besed smo torej usmerjeni samo k logično oštevilčeni iztočnici, npr. pri besedi lekarna je kazalka na 3797 (iztočnica apoteka). 
menskega polja $-\mathrm{v}$ navedenem primeru Veřejná správa, ki pa je $\mathrm{v}$ diferencialnem slovarju ne najdemo). Tako kot $\mathrm{v}$ semaziološko zasnovanem diferencialnem slovarju je tudi v onomaziološkem delu tisk izrazito negospodaren, saj so besede nanizane druga pod drugo $v$ stolpec, na eni strani v knjigi pa sta dva taka stolpca.

V diferencialnem slovarju prevladujejo samostalniki in glagoli, druge besedne vrste so redko zastopane (najdemo npr. prisl. durch 'vseskozi' in hindá 'drugje', prid. hostaté 'utrujen' ...), podobno je tudi v onomaziološko zasnovanem delu.

Podobno kot predstavljeni slovar J. Vojtove sta zgrajena tudi že omenjena češka narečna slovarja Jarmile Bachmannove (1998) in Zdeňke Sochove (2001), ki ju Vojtová oba tudi navaja v seznamu literature in se nanju sklicuje pri razvrstitvi besedja $\mathrm{v}$ pomenska polja. $\mathrm{V}$ primerjavi s tema slovarjema, $\mathrm{v}$ katerih iz onomaziološko zasnovanega indeksa ne moremo ugotoviti, katero besedo bomo našli tudi $\mathrm{v}$ diferencialnem slovarju, je v predstavljenem slovarju J. Vojtove iskanje lažje zaradi zapisa takih besed v krepkem slogu. V slovarju Z. Sochove manjkajo tudi kazalke iz diferencialnega slovarja na ideografski indeks, tako da besed, ki jih najdemo $\mathrm{v}$ diferencialnem slovarju, ne najdemo enostavno $\mathrm{v}$ razvrstitvi po pomenskih poljih, kar je Vojtová nadgradila s kazalko v vsakem geslu, enako rešitev pa najdemo že pri J. Bachmannovi. Če sta slovarja Z. Sochove in J. Bachmannove precej bolj gospodarna s prostorom, pa je slovar J. Vojtove bogatejši za zelo uporabno abecedno kazalo vključenih izrazov s kazalkami na onomaziološki del slovarja.

Delo J. Vojtove je dober metodološki prispevek k narečnemu slovaropisju, koristno izhodišče za nadaljnje bohemistične in širše (primerjalno)slavistične študije, bogato narečno gradivo pa tudi za druge znanstvene stroke. Delo je vsekakor velik prispevek k ohranjanju kulturne dediščine obravnavanega področja in vsestransko zanimivo za ljubitelje čeških narečij.

\section{Literatura}

Bachmannová 1998 = Jarmila Bachmannová, Podkrkonošský slovnik, Praha: Academia, 1998.

Bachmannová 2009 = Jarmila Bachmannová, Jarmila Vojtová: Slovnik středomoravského nařečí horského typu, v: Naše řeč (Brno) 92 (2009), št. 1, 35-38.

Bertram 1997 = Anne Bertram, NTC's Dictionary of Commonplace Words in RealLife Contexts: an Essential Guide to the Everyday Objects in American Life, Lincolnwood, Illinois: NTC Publishing Group, 1997.

Blažeka 2008 = Đuro Blažeka, Prijedlog koncepcije izrade rječnika poljoprivrednog nazivlja u međimurskom dijalektu, Croatica et Slavica Iadertina (Zadar) 4 (2008), 157-180.

Bokal 2003 = Ljudmila Bokal, Slovenski narečni slovarji, v: Zinka Zorko - Mihaela Koletnik (ur.), Glasoslovje, besedoslovje in besedotvorje v delih Jakoba Riglerja Maribor: Slavistično društvo, 2003 (Zora 25), 24-42.

Dornseiff $1970=$ Franz Dornseiff, Der deutsche Wortschatz nach Sachgruppen, Berlin - New York: Walter de Gruyter, 1970. 
Hartmann - James 1998 = R. R. K. Hartmann - Gregory James, Dictionary of Lexicography, London - New York: Routledge, 1998.

Jovanović - Atanacković 1980 = Ranko Jovanović - Laza Atanacković, Sistematski rečnik srpskohrvatskoga jezika, Subotica: Minerva, 1980.

Kenda-Jež - Weiss 1999 = Karmen Kenda-Jež - Peter Weiss, Posebnosti (slovenskega) narečnega slovaropisja, v: Seminar slovenskega jezika, literature in kulture: zbornik predavanj 35 (1999), 27-46.

Kloferová 2009 = Stanislava Kloferová, Jarmila Vojtová: Slovnik středomoravského nařečí horského typu, v: Linguistica Brunensia (Brno) 57 (2009), št. 1-2, 306-309.

Matejčík 1975 = Ján Matejčík, Lexika Novohradu: vecný slovník, Banská Bystrica: Osveta, 1975.

Ostromęcka-Frączak 2007 = Bożena Ostromęcka-Frączak, Historia leksykografii słoweńskiej, Łódź: Wydawnictwo Uniwersytetu Łódzkiego, 2007.

Sochová 2001 = Zdeňka Sochová, Lašská slovní zásoba, Praha: Academia, 2001.

Wehrle - Eggers 1993 = Hugo Wehrle - Hans Eggers, Deutscher Wortschatz: ein Wegweiser zum treffenden Ausdruck, Stuttgart - Dresden: Ernst Klett Verlag für Wissen und Bildung, 1993.

Weiss 2003 = Peter Weiss, Uvod v slovenski narečni slovar, v: Jezikoslovni zapiski 9 (2003), št. 1, 49-61. 